\title{
AISLAMIENTO E IDENTIFICACIÓN DE BACTERIAS CELULOLÍTICAS TERMÓFILOS DE GÉISERES NATURALES DE CANDARAVE - TACNA
}

\author{
ISOLATION AND IDENTIFICATION OF THERMOPHILIC CELLULOLYTIC \\ BACTERIA FROM NATURAL GEYSERS CANDARAVE - TACNA
}

${ }^{1}$ Helena Beatriz Zapata Málaga; ${ }^{2}$ Roberto Castellanos Cabrera

\begin{abstract}
RESUMEN
Se realizó el aislamiento de 31 cultivos bacterianos a partir de las fuentes termales de Calientes, seleccionándo los cultivos que presentaron diámetros significativos de las zonas de hidrólisis y la mayor actividad de endoglucanasas en cultivo sumergido, inducidas con $\mathrm{CMC} 1 \%$. Las cepas seleccionadas B12N y B20A tienen una actividad máxima de endoglucanasas termoestables, con interés industrial, de $0,56 \mathrm{UI} \mathrm{ml}^{-1}$ a $67,5^{\circ} \mathrm{C}$ y un pH 5,9 y $0,27 \mathrm{UI} \mathrm{ml}^{-1}$ a $59,5^{\circ} \mathrm{C}$ y un pH 6,4 respectivamente; la cepa $\mathrm{B} 12 \mathrm{~N}$ presenta la mayor pureza enzimática con 18,66 UI mg ${ }^{-1}$ de proteina. Además se presentó una similitud con el gen ARNr $16 \mathrm{~S}$ de Geobacillus sp. al $99 \%$ y con el de Bacillus licheniformis al $97 \%$ para la cepa B12N y B20A respectivamente tras su secuenciamiento.
\end{abstract}

Palabras clave: Bacillus licheniformis, endoglucanasas, gen ARNr 16S, Geobacillus sp., termoestables.

\begin{abstract}
Isolation of 31 bacterial cultures were performed from Calientes hot springs, selecting the cultures that showed significant diameters of hydrolyzed zones and the highest amount of endoglucanases activity in submerged culture, induced with CMC $1 \%$. The selected strains B12N and B20A have a maximum activity of thermostable endoglucanases, with an industrial importance, of $0,56 \mathrm{UI} \mathrm{ml}^{-1}$ at $67,5^{\circ} \mathrm{C}$ and $\mathrm{pH} 5,9$ and $0,27 \mathrm{UI} \mathrm{ml}^{-1}$ at $59,5^{\circ} \mathrm{C}$ and $\mathrm{pH} 6,4$ respectively; the strain $\mathrm{BI} 2 \mathrm{~N}$ presents the highest enzyme purity with 18,66 UI mg of protein. Also was presented a similarity with the $16 \mathrm{~S} \mathrm{rRNA} \mathrm{gene} \mathrm{of} \mathrm{Geobacillus} \mathrm{sp.} \mathrm{at} 99 \%$ and with Bacillus licheniformis at $97 \%$ for the strain $\mathrm{B} 12 \mathrm{~N}$ and $\mathrm{B} 20 \mathrm{~A}$ respectively after their sequencing.
\end{abstract}

Key words: Bacillus licheniformis, endoglucanases, 16S rRNA gene, Geobacillus sp., thermostables.

\section{INTRODUCCIÓN}

La importancia del estudio de la diversidad microbiana radica en la participación activa sobre los ciclos biogeoquímicos, gracias a la cual se recupera y recicla materia y energía por medio de enzimas y complejos enzimáticos específicos que poseen dichos microorganismos, entre ellos se encuentran los microorganismos celulolíticos en el reciclaje de la celulosa (Hongpattarakere, 2002), la cual es una de las moléculas poliméricas más abundantes en la biósfera (Martínez et al., 2005; Pérez et al., 2002; Hernández et al., 1999) y con alto potencial de bioconversión a biocombustibles (Bhalla et al., 2013).

La hidrólisis eficiente de la celulosa implica la operación secuencial y la acción sinergista de al menos tres enzimas. De acuerdo al sitio en el que cortan la fibrilla de celulosa se clasifican en tres grandes grupos: endo $\beta-1,4$ glucanasas $(\beta-1,4$ glucano glucanohidrolasa), exo $\beta-1,4$ celobiohidrolasas y las $\beta-1,4$ glucosidasas (Lymar et al., 1995; Zhang et al., 2006). Estas enzimas pueden ser secretadas por una serie de microorganismos como hongos y bacterias, sin embargo la utilización de la celulosa requiere que los microorganismos tengan celulasas extracelulares que sean fácilmente recuperables del sobrenadante del cultivo (Lynd et al., 2002), además de mantener su actividad hidrolítica ante una serie de factores físicos y químicos que limitan su aplicación a nivel industrial, como las elevadas temperaturas de reacción.

Siendo consideradas las bacterias termófilas prometedoras en la degradación de celulosa, por la termoestabilidad de sus enzimas, es de gran importancia la selección de estos microorganismos con una eficiente actividad celulolitica para obtener sustancias biológicamente activas con interés biotecnológico e industrial.

Con la identificación de microorganismos con utilidad económica, se proveerá a las fuentes termales de Calientes, de la provincia de Candarave, departamento de Tacna, un valor económico en términos de riqueza genética.

\section{MATERIALES Y MÉTODOS}

Ubicación y delimitación del área de estudio

El área de estudio comprendió la zona geotermal de Calientes, ubicada en la provincia de Candarave, región 
Tacna, la cual se encuentra a 4400 msnm, al occidente de la cordillera de los Andes en el sur de Perú (Cruz et al., 2010).

En dicha zona se encuentran las ocho fuentes termales muestreadas, las cuáles mostraron las más altas temperaturas de 60 a $88{ }^{\circ} \mathrm{C}, \mathrm{pH}$ entre 7,1 y 7,5 y tenían presencia de tapetes microbianos, biopelículas y fango.

\section{Colección de muestra}

Se colectaron en total $1 \mathrm{~L}$ (de 2 puntos de muestreo por fuente termal) de las muestras de fango, biopelículas o tapetes microbianos de las 8 fuentes termales de Calientes y fueron transportadas en termos estériles de $1 \mathrm{~L}$ para su procesamiento.

\section{Aislamiento}

Se realizó un enriquecimiento de la biodiversidad procariota termofilica con actividad de celulasas de las muestras con el método modificado de Kublanov et al. (2009). Se agregó a las muestras $1 \%(\mathrm{p} / \mathrm{v})$ de celulosa microcristalina y se incubó a $100 \mathrm{rpm}$, por 14 días a $70^{\circ} \mathrm{C}$ para las muestras $\mathrm{T} 1$ - $\mathrm{T} 5 \mathrm{y} \mathrm{a} 60^{\circ} \mathrm{C}$ para las muestras $\mathrm{T} 6$ - T8. Luego se procedió a la siembra por incorporación de la muestra y se incubó a $60{ }^{\circ} \mathrm{C}$ por 10 días. El medio de aislamiento contenía por litro: (NH4) ${ }_{2} \mathrm{SO}_{4} 11,7 \mathrm{~g}, \mathrm{KH}_{2} \mathrm{PO} 4$ $3,7 \mathrm{~g}, \mathrm{MgSO}_{4} .7 \mathrm{H}_{2} \mathrm{O} 0,6 \mathrm{~g}, \mathrm{CaCl}_{2} \cdot 2 \mathrm{H}_{2} \mathrm{O} 0,8 \mathrm{~g}$, extracto de Levadura $0,5 \mathrm{~g}$, peptona $0,5 \mathrm{~g}, \mathrm{FeSO}_{4} .7 \mathrm{H}_{2} \mathrm{O} 500 \mathrm{mg}$, $\mathrm{MnSO}_{4} \cdot \mathrm{H}_{2} \mathrm{O} 160 \mathrm{mg}, \mathrm{ZnSO}_{4} .7 \mathrm{H}_{2} \mathrm{O} 140 \mathrm{mg}, \mathrm{CoCl} .6 \mathrm{H}_{2} \mathrm{O} 370$ $\mathrm{mg}, \mathrm{CMC} 10 \mathrm{~g}$ y agar $20 \mathrm{~g}$; el pH fue ajustado a $7 \mathrm{con} \mathrm{NaOH}$ $1 \mathrm{~N}$.

Las colonias crecidas fueron estriadas para luego ser almacenadas en agar nutritivo y conservadas a $4{ }^{\circ} \mathrm{C}$. Para la identificación microscópica se realizó la coloración Gram.

\section{Actividad cualitativa de celulasas}

Fue desarrollada en base al método de Teather y Wood (1982). Para ello, se sembró por incorporación $20 \mu \mathrm{l}$ de inóculo (D.O. de 0,3 ) en $150 \mu$ de medio de producción de celulasas descrito por Mandels y Reese (1957): $\left(\mathrm{NH}_{4}\right)_{2} \mathrm{SO}_{4}$ $0,14 \%, \mathrm{KH}_{2} \mathrm{PO}_{4} 0,2 \%, \mathrm{MgSO}_{4} .7 \mathrm{H}_{2} \mathrm{O} 0,03 \%, \mathrm{CaCl}_{2} 0,03 \%$, $\mathrm{Co}\left(\mathrm{NH}_{2}\right)_{2} 0,03 \%, \mathrm{FeSO}_{4} .7 \mathrm{H}_{2} \mathrm{O} 500 \mathrm{mgL}^{-1}, \mathrm{MnSO}_{4} . \mathrm{H}_{2} \mathrm{O} 160$ $\mathrm{mg} \mathrm{L}^{-1}, \mathrm{ZnSO}_{4} \cdot 7 \mathrm{H}_{2} \mathrm{O} 140 \mathrm{mg} \mathrm{L}^{-1}, \mathrm{CoCl}_{2} 200 \mathrm{mg} \mathrm{L}^{-1}$, peptona $0,1 \%$, extracto de levadura $0,1 \%$, CMC $0,5 \%$, se agregó agar al $2 \%(\mathrm{p} / \mathrm{v})$, se ajustó el $\mathrm{pH}$ a 7 con $\mathrm{NaOH} 1 \mathrm{~N}$. Se sembró en microplacas ELISA de fondo plano de 96 pozos (LabSource, Arbor, IL, USA) y se incubaron a $60^{\circ} \mathrm{C}$ por 72 h. El contenido de cada pocillo (después de comprobar el crecimiento del microorganismo) se retiró con un sacabocado estéril y se colocó sobre placas de vidrio, que contenían los medios sólidos con el sustrato de celulasas (Meza et al., 1995), incubándose $70^{\circ} \mathrm{C}$ en baño María por $4 \mathrm{~h}$.

Los medios sólidos con el sustrato para celulasas contenían: $\mathrm{CMC}$ al $0,5 \%(\mathrm{p} / \mathrm{v})$ y agar al $2 \%(\mathrm{p} / \mathrm{v})$ disueltos en tampones a $\mathrm{pH} 4,8 ; 7,4 ; 8,4$ y 9,4 a $0,05 \mathrm{M}$ de acetato de sodio, fosfato de sodio, barbital - $\mathrm{HCl}$ y glicina $\mathrm{NaOH}$ respectivamente.

Para el revelado de las zonas de hidrólisis por las celulasas, se agregó una solución de Rojo Congo al $0,1 \%$ $(\mathrm{p} / \mathrm{v})$ hasta cubrir toda la placa, se dejó a temperatura ambiente por $15 \mathrm{~min}$ y luego se retiró el exceso de colorante lavando con $\mathrm{NaCl} 1 \mathrm{M}$. Se evidenció la actịidad enzimática por la difusión de la enzima, presente en el disco de agar sobre el medio de tamizado por la presencia de zonas transparentes no teñidas.

\section{Actividad cuantitativa de celulasas}

Se inoculó $3 \%(\mathrm{v} / \mathrm{v})$ de caldo nutritivo con crecimiento bacteriano (D.O. de 0,3) en matraces con deflectores de $250 \mathrm{ml}$ con $40 \mathrm{ml}$ de medio de producción con CMC $1 \%$ (p/v) ajustado a $\mathrm{pH} 7$ con $\mathrm{NaOH} 1 \mathrm{~N}$. Se incubó a $150 \mathrm{rpm}$ por 48 horas a $60 \pm 5{ }^{\circ} \mathrm{C}$. El cultivo obtenido se centrifugó a $6000 \mathrm{rpm}$ por $20 \mathrm{~min}$, el sobrenadante fue utilizado para la actividad enzimática y medición de proteínas solubles y el sedimento para la medición de biomasa.

Se midió la actividad de la enzima endoglucanasa por el método descrito por Ghose (1987). Para ello a $0,5 \mathrm{ml}$ del sobrenadante se añadió $1 \mathrm{ml}$ de diferentes tampones a $\mathrm{pH} 4,8 ; 7,4$ y 8,4 a $0,05 \mathrm{M}$ de acetato de sodio, fosfato de sodio y barbital - $\mathrm{HCl}$, respectivamente, y se incubó por 5 minutos a $70^{\circ} \mathrm{C}$, luego se agregó $1 \mathrm{ml}$ de CMC al $1 \%(\mathrm{p} / \mathrm{v})$ y se incubó dicho sistema a $70^{\circ} \mathrm{C}$ durante $30 \mathrm{~min}$. Se midió la liberación de azúcares reductores, expresada en UI $\mathrm{ml}^{-1}$, donde una unidad de enzima se define como la cantidad de enzima que libera $1 \mu \mathrm{mol}$ de glucosa por minuto (Miller, 1959).

Se optimizó la actividad enzimática de endoglucanasas de las cepas seleccionadas con mayor actividad enzimática, evaluándose en los diferentes tampones a $50 \mathrm{mM}$ : acetato de sodio $\mathrm{pH} 4,4$ y 5,4 ; fosfato de sodio $\mathrm{pH} \mathrm{6,4} \mathrm{y} \mathrm{7,4;} \mathrm{barbital} \mathrm{-} \mathrm{HCl}$ pH 8,4 y glicina $\mathrm{NaOH}$ pH 9,$4 ; y$ a diferentes temperaturas de $50^{\circ} \mathrm{C}$ a $80^{\circ} \mathrm{C}$.

\section{Determinación de biomasa celular}

Se determinó la biomasa celular según el método descrito por Ramírez y Coha (2003), utilizando la diferencia de pesos entre los tubos con biomasa sedimentada y secada a $100{ }^{\circ} \mathrm{C}$ durante 24 horas y los tubos vacíos secados. La biomasa fue expresada en $\mathrm{mg} \mathrm{ml}^{-1}$.

\section{Cuantificación de proteinas solubles}

Las muestras fueron previamente tratadas por el método descrito por Wessel y Fluegge (1984), para ello fueron centrifugadas para remover los sólidos y usar el sobrenadante, el cual se precipitó con TCA al $10 \%(\mathrm{p} / \mathrm{v})$ en una relación de $2: 1$ respectivamente, se incubó toda la noche a $4{ }^{\circ} \mathrm{C}$ y luego se centrifugó por $20 \mathrm{~min}$ a $6000 \mathrm{rpm}$ descartándose el sobrenadante y se disolvió el sedimento en $1 \mathrm{ml}$ de solución de $\mathrm{Na}_{2} \mathrm{CO}_{3}$ al $2 \%$ en $0,1 \mathrm{M}$ de $\mathrm{NaOH}$.

La cuantificación de proteínas solubles fue realizada mediante el método de Lowry et al. (1951), utilizándose una solución de seroalbúmina bovina $\left(1 \mathrm{mg} \mathrm{ml}^{-1}\right)$ como estándar.

\section{Extracción de ADN y reacción en cadena de la polimerasa (PCR)}

El ADN de las cepas seleccionadas fue extraído en base al método descrito por Sambrook y Russell (1989). Se usó $10 \mathrm{ml}$ de un cultivo joven de 18 horas el cual fue centrifugado a $14000 \mathrm{rpm}$ por $10 \mathrm{~min}$, al pellet obtenido se añadió $100 \mu \mathrm{l}$ de TES (Tris $10 \mathrm{mM}$, EDTA $1 \mathrm{mM}, \mathrm{pH} 8$, sacarosa $25 \%$ ) sacarosa $25 \%$ ), $40 \mu \mathrm{l}$ de lisozima $\left(5 \mathrm{mg} \mathrm{ml}^{-1}\right)$ y 
Zapata, H. y Castellanos, R., Aislamiento e identificación de bacterias celulolíticas termófilos de géiseres naturales de Candarave - Tacna.

$40 \mu \mathrm{l}$ de EDTA 0,25 M, después de ser incubado a $37^{\circ} \mathrm{C}$ por 10 min se agregó $175 \mu \mathrm{l}$ de agua ultrapura, $50 \mu \mathrm{l}$ de SDS al 10 $\%$ y 5 ul de RNAsa $\left(10 \mathrm{mg} \mathrm{ml}^{-1}\right)$, se mezcló e incubó a $37^{\circ} \mathrm{C}$ por $20 \mathrm{~min}$, luego se añadió $10 \mu \mathrm{l}$ de proteinasa $\mathrm{K}\left(10 \mathrm{mg} \mathrm{ml}^{-}\right.$ $\left.{ }^{1}\right)$ y tras incubarse a $37^{\circ} \mathrm{C}$ por $30 \mathrm{~min}$ se agregó $85 \mu \mathrm{l}$ de TE (tris $10 \mathrm{mM}$, EDTA $1 \mathrm{mM}$, pH 8), $120 \mu \mathrm{l}$ de $\mathrm{NaCl} 5 \mathrm{M}$, se mezcló e incubó a $65^{\circ} \mathrm{C}$ por $20 \mathrm{~min}$. Seguidamente se añadió $75 \mu \mathrm{l}$ de acetato de potasio $8 \mathrm{M}$ y se homogenizó por inversión del tubo, luego se incubó a $4{ }^{\circ} \mathrm{C}$ por 15 min y se centrifugó a $14000 \mathrm{rpm}$ por $5 \mathrm{~min}$. El material genético se encuentra en el sobrenadante obtenido, el cual fue transferido a un tubo nuevo, se agregó etanol absoluto al $95 \%$ hasta llenar el tubo y se dejó precipitar el ADN durante toda la noche a -20 ${ }^{\circ} \mathrm{C}$, luego se centrifugó a 14000 rpm por 30 min, se descartó el sobrenadante y el sedimento obtenido fue lavado con etanol al $70 \%$, se centrifugó a $14000 \mathrm{rpm}$ por $30 \mathrm{~min}$.

Se descartó el sobrenadante y el sedimento seco fue eluido en $50 \mu \mathrm{l}$ de TE (Tris $25 \mathrm{mM}$, EDTA $1 \mathrm{mM}, \mathrm{pH}$ 8).

La reacción en cadena de la polimerasa (PCR) fue realizada siguiendo el protocolo descrito por el kit GoTaq Flexi DNA Polymerase (Promega). Se usó $4 \mu \mathrm{l}$ de Buffer
Green Flexi, $2 \mu \mathrm{l}$ de $\mathrm{MgCl} 225$ mM; 1,2 $\mu \mathrm{l}$ de dNTPs $10 \mathrm{mM}$;

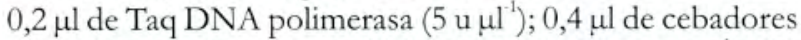
ARNr $16 \mathrm{~S} 10 \mu \mathrm{M}$ (27F y 1492R), $3 \mu \mathrm{l}$ de ADN 50 ng $\mu \mathrm{l}^{-1}$ y 8,8 $\mu \mathrm{l}$ de agua Depc.

Las secuencias de los cebadores ARNr 16S utilizados para la reacción de PCR fueron: $27 \mathrm{~F}$ AGAGTTTGATCCTGGCTCAG y 1492 RGGTTACCTTGTTACGACT'T.

Se usó el Termociclador S1000 (BioRad), programado para una desnaturalización inicial a $95^{\circ} \mathrm{C}$ por 4 min y 40 ciclos con desnaturalización a $95^{\circ} \mathrm{C}$ por $1 \mathrm{~min}$, hibridización a $55^{\circ} \mathrm{C}$ por $1 \mathrm{~min}$ y polimerización a $72^{\circ} \mathrm{C}$ por 1 min para el gen ARNr $16 \mathrm{~S}$. Se realizó una extensión a $72^{\circ} \mathrm{C}$ por $5 \mathrm{~min}$.

\section{Análisis estadístico}

Para el análisis de los datos obtenidos se realizó el análisis de varianza (ANVA) empleando la prueba $F$ a un nivel de 0,05 de probabilidad. La comparación de las medias entre los tratamientos se realizó con la prueba de significación de Duncan al $95 \%$ de confiabilidad.

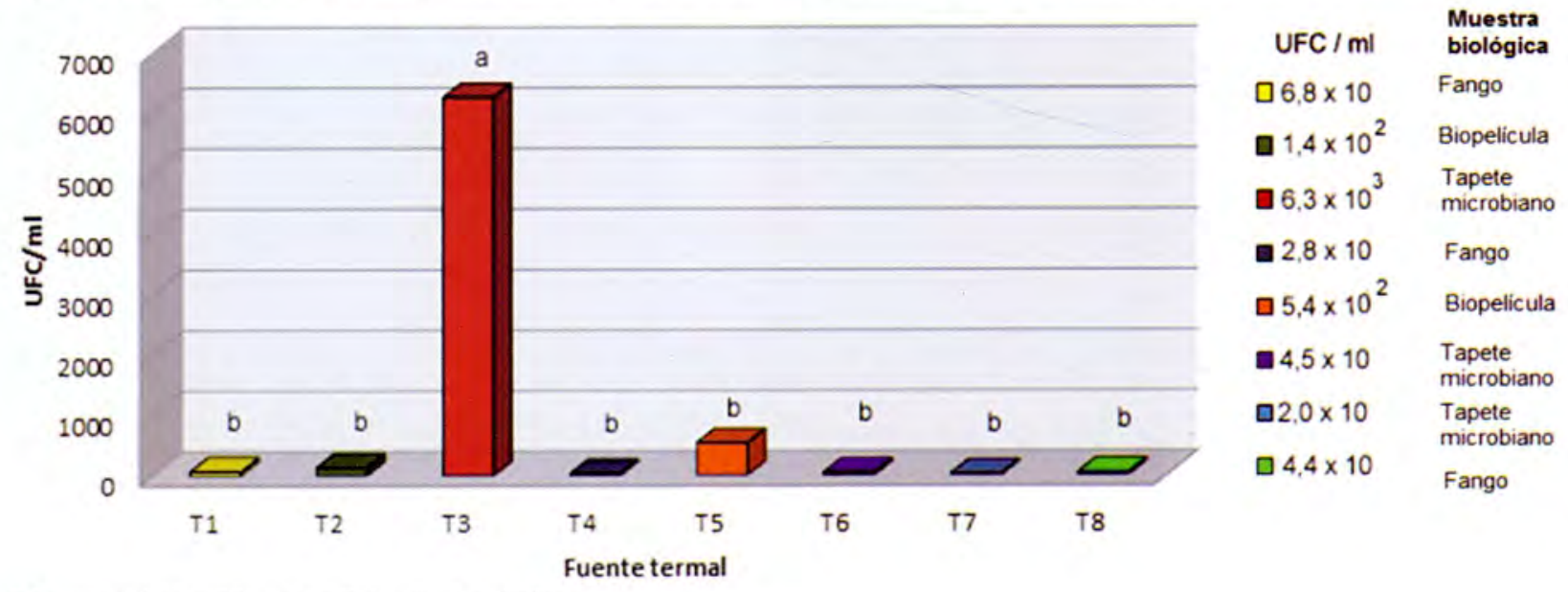

* Letras iguales no difieren estadísticamente $\mathrm{p}<0,05$.

Figura $\mathrm{N}^{\circ} 01$. Recuento de UFC de las fuentes termales de Calientes.

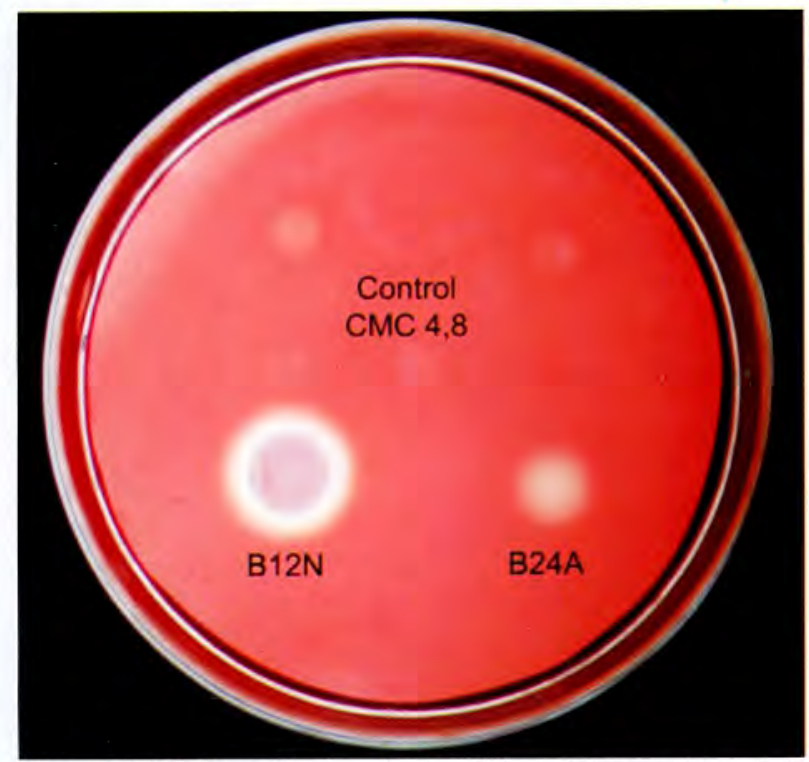

Figura $\mathrm{N}^{\circ} 02$. Actividad cualitativa de las celulasas evidenciada por zonas de hidrólisis desteñidas de las cepas B12N y B20A.
Para la optimización de los factores experimentales ( $\mathrm{pH}$ y temperatura) de la actividad celulolítica termófila de las cepas seleccionadas, se usó el software Statgraphics Centurion XVI, realizándose el análisis de regresión.

\section{RESULTADOS}

\section{Aislamiento}

Las muestras de las 8 fuentes termales mostraron variabilidad de cultivos bacterianos y heterogeneidad de población (Figura 01). Se aislaron 31 cultivos bacterianos, donde el 61,29\% fueron Gram positivo y el 38,71 \% Gram negativo y la mayoría presentaron colonias cremosas circulares de color crema o beige.

\section{Actividad cualitativa de celulasas}

$\mathrm{La}$ actividad cualitativa de las celulasas de los 31 cultivos aislados, usando CMC como sustrato a $\mathrm{pH} 4,8 ; 7,4$; 8,4 y 9,4 ; se evidenció por las zonas de hidrólisis representadas por áreas desteñidas que indican la acción del rompimiento de los enlaces $\beta-1,4$ de la celulosa y presencia 


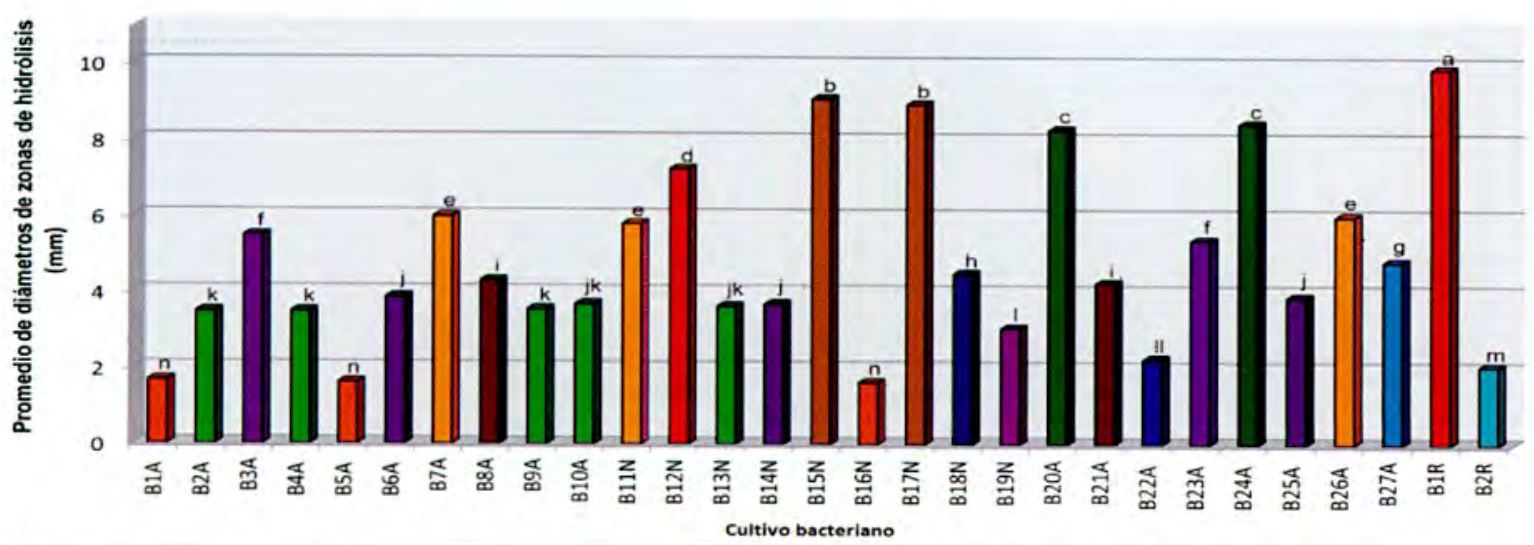

${ }^{*}$ Letras iguales no difieren estadísticamente $\mathrm{p}<0,05$.

Figura $\mathrm{N}^{\circ}$ 03. Diámetro de zona de hidrólisis de celulasas de los cultivos bacterianos aislados.

de endoglucanasas (Figura $\mathrm{N}^{\circ} 02$ ).

Existe diferencia estadísticamente significativa entre la media de la variable de diámetro de las zonas de hidrólisis de celulasas, a diferentes valores de $\mathrm{pH}$, entre un nivel de cultivo bacteriano y otro, con un nivel de confianza del $95 \%$ (Figura $\mathrm{N}^{\circ} 03$ ).

Se pre-seleccionaron 6 cultivos, para su posterior análisis, las cuales mostraron altos promedios superiores a 7 $\mathrm{mm}$, debido a su actividad en casi todos los valores de $\mathrm{pH}$ evaluados, indicando estabilidad de la enzima.

\section{Actividad cuantitativa de celulasas}

De los cultivos pre-seleccionados fueron seleccionadas las cepas B12N y B20A, las cuales presentaron mayor actividad de endoglucanasas.

Los efectos de los factores $\mathrm{pH}$ y temperatura en la actividad termófila enzimática, indicaron variabilidad significativa con un nivel de confianza del $95 \%$. Se observó que los factores incluidos en el modelo están explicando el $58,42 \%$ de la variabilidad de la actividad enzimática para la cepa B12N y el $76 \%$ para la cepa B20A (Tabla N 01 , Tabla

Tabla $\mathbf{N}^{\circ}$ 01. Análisis de varianza para la actividad de endoglucanasas de la cepa B12N

\begin{tabular}{cccccc}
\hline Fuente & S.C. & G.I. & C.M. & Razón F & Valor P \\
\hline $\mathrm{pH}$ & 0,10757 & 1 & 0,1076 & 17,01 & 0,0002 \\
$\mathrm{~T}$ & 0,09290 & 1 & 0,0929 & 14,69 & 0,0004 \\
$\mathrm{pH}^{2}$ & 0,13453 & 1 & 0,1345 & 21,27 & 0,0000 \\
$\mathrm{~T}^{2}$ & 0,12573 & 1 & 0,1257 & 19,88 & 0,0001 \\
Error total & 0,28457 & 45 & 0,0063 & &
\end{tabular}

Tabla $\mathbf{N}^{\circ}$ 02. Análisis de varianza para la actividad enzimática de endoglucanasas de la cepa B20A

\begin{tabular}{cccccc}
\hline Fuente & S.C. & G.I. & C.M. & Razón F & Valor P \\
\hline $\mathrm{pH}$ & 0,018019 & 1 & 0,01802 & 11,26 & 0,0013 \\
$\mathrm{~T}$ & 0,127990 & 1 & 0,12799 & 79,99 & 0,0000 \\
$\mathrm{pH}^{2}$ & 0,035485 & 1 & 0,03549 & 22,18 & 0,0000 \\
$\mathrm{~T}^{2}$ & 0,184736 & 1 & 0,18474 & 115,45 & 0,0000 \\
Error total & 0,107211 & 67 & 0,00160 & & \\
\hline
\end{tabular}

$\left.\mathrm{N}^{\circ} 02\right)$.

Se obtuvo las siguientes funciones de respuesta (ecuación de regresión) a utilizar que se han ajustado a los datos para maximizar los factores de $\mathrm{pH}$ y temperatura (T):

$\mathbf{A E}(\mathbf{B} 12 \mathbf{N})=-5,96512+0,36398 \mathrm{pH}+0,161724 \mathrm{~T}-$ $0,0309982 \mathrm{pH}^{2}-0,0011987 \mathrm{~T}^{2}$

$\mathbf{A E}(\mathbf{B 2 0 A})=-2,96175+0,11356 \mathrm{pH}+0,096595 \mathrm{~T}-$ $0,008899 \mathrm{pH}^{2}-0,0008123 \mathrm{~T}^{2}$

De las ecuaciones obtenidas se obtuvo para la cepa B12N el valor óptimo de $\mathrm{pH} 5,9$ y temperatura $67,5^{\circ} \mathrm{C}$, dando un valor maximizado de actividad enzimática de endoglucanasas de $0,56 \mathrm{UI} \mathrm{ml}^{-1}$ (Figura $\mathrm{N}^{\circ} 04$ ). Mientras que para la cepa B20A se obtuvo el valor óptimo de $\mathrm{pH} 6,4$ y temperatura $59,5^{\circ} \mathrm{C}$, dando un valor maximizado de $0,27 \mathrm{UI}$ $\mathrm{ml}^{-1}$ (Figura $\mathrm{N}^{\circ} 05$ ).

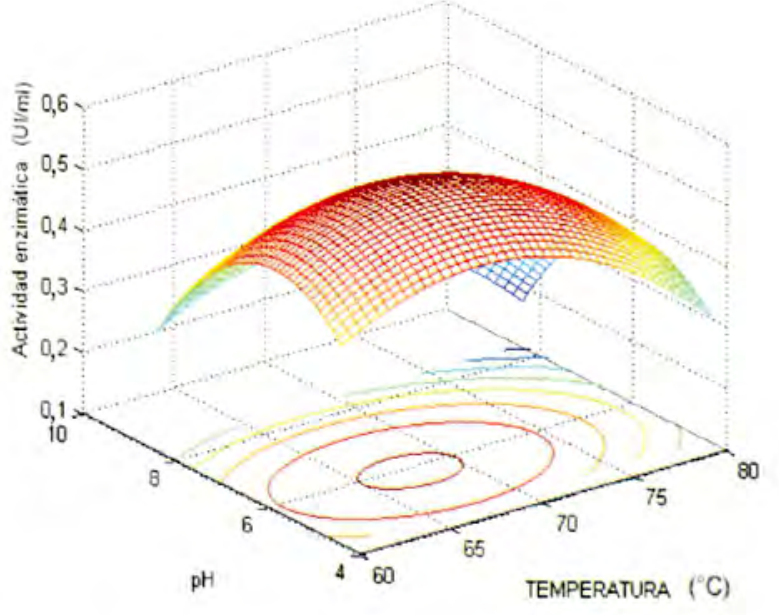

Figura $\mathbf{N}^{\circ}$ 04. Superficie respuesta estimada de la optimización de la actividad enzimática de endoglucanasas de la cepa B12N. 
Zapata, H. y Castellanos, R., Aislamiento e identificación de bacterias celulolíticas termófilos de géiseres naturales de Candarave - Tacna.

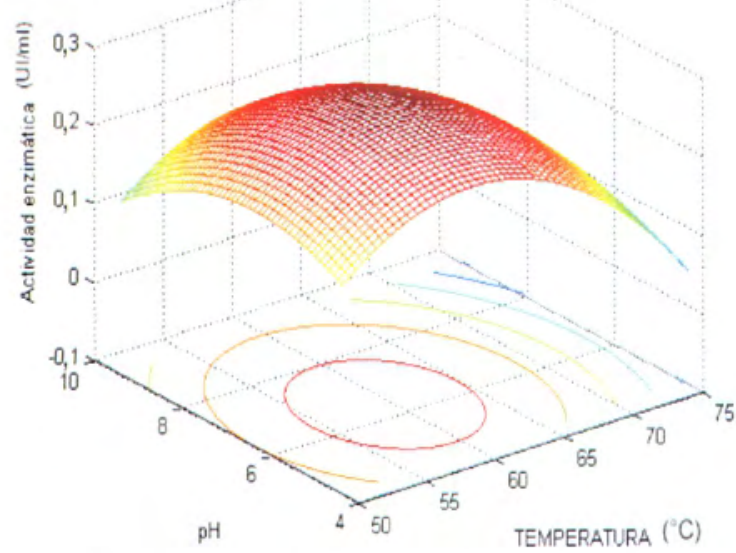

Figura $\mathrm{N}^{\circ} \mathbf{0 5}$. Superficie respuesta estimada de la actividad enzimática de endoglucanasas de la cepa B20A.

Tabla $\mathrm{N}^{\mathbf{0}}$ 03. Parámetros de productividad de endoglucanasas de las cepas B12N y B20A

\begin{tabular}{cccc}
\hline Cepa & $\begin{array}{c}\text { Proteina } \\
\left(\mathrm{mg} \mathrm{ml}^{-1}\right)\end{array}$ & $\begin{array}{c}\text { AEP* (UI mg de } \\
\text { proteina }\end{array}$ & $\begin{array}{c}\text { AEB* (UI mg de } \\
\text { biomasa }\end{array}$ \\
\hline B12N & 0,03 & 18,66 & 11,2 \\
B20A & 0,25 & 1,08 & 4,5 \\
\hline
\end{tabular}

* AEP: Actividad específica, AEB: Rendimiento.

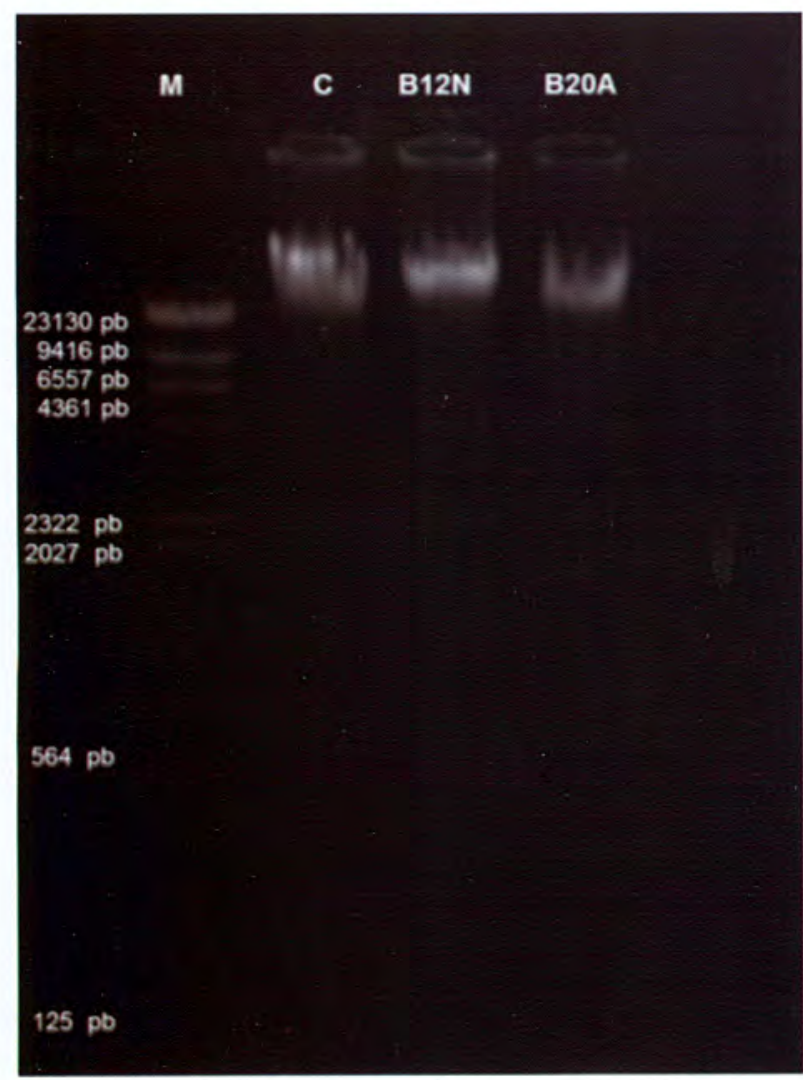

* M: marcador Hind III de 23130 pb, C: cepa control Escherichia coli.

Figura $\mathrm{N}^{\circ}$ 06. Electroforesis del ADN de las cepas B12N y B20A.
Determinación de biomasa celular y cuantificación de proteínas solubles

Extracción de ADN y reacción en cadena de la polimerasa (PCR)

El ADN extraído de la cepa B12N presentó 28 576,764 pb, de la cepa B20A 24385,68 pb, y del control 24 385,68 pb (Figura N $\left.{ }^{\circ} 06\right)$.

Se visualizó el producto de PCR amplificado y purificado mediante electroforesis, donde el ADN de la cepa B20A presentó 1481,817 pb, el de la cepa B12N presentó 1 521,013 pb y del control 1501,287 pb, valores que coinciden con el tamaño del ARNr 16S (Figura $\mathrm{N}^{\circ}$ 07).

Análisis del secuenciamiento del ARNr16S

El resultado del secuenciamiento del gen $\mathrm{ARNr}$ 16S informa sobre la identidad de la bacteria con la depositada en la base de datos de GenBank (búsqueda en

Tabla $N^{\circ} 04$. Similitud de secuencias de ARNr 16S para las cepas B12N y B20A en BLASTN

\begin{tabular}{|c|c|c|c|c|}
\hline \multirow[b]{2}{*}{ Cepa } & \multicolumn{4}{|c|}{ Pariente más cercano en BLASTN } \\
\hline & Descripción & $\begin{array}{c}\text { Cobertura } \\
\% \\
\end{array}$ & Evalue & $\begin{array}{c}\text { Identidad } \\
\%\end{array}$ \\
\hline $\mathrm{B} 12 \mathrm{~N}$ & $\begin{array}{l}\text { Geobacillus sp. JC106 partial } \\
\text { 16S rRNA gene, strain JC106 }\end{array}$ & 99 & 0,0 & 99 \\
\hline $\mathrm{B} 20 \mathrm{~A}$ & $\begin{array}{l}\text { Bacillus licheniformis strain F3 } \\
16 \mathrm{~S} \text { ribosomal RNA gene, } \\
\text { partial sequence }\end{array}$ & 97 & 0,0 & 97 \\
\hline
\end{tabular}

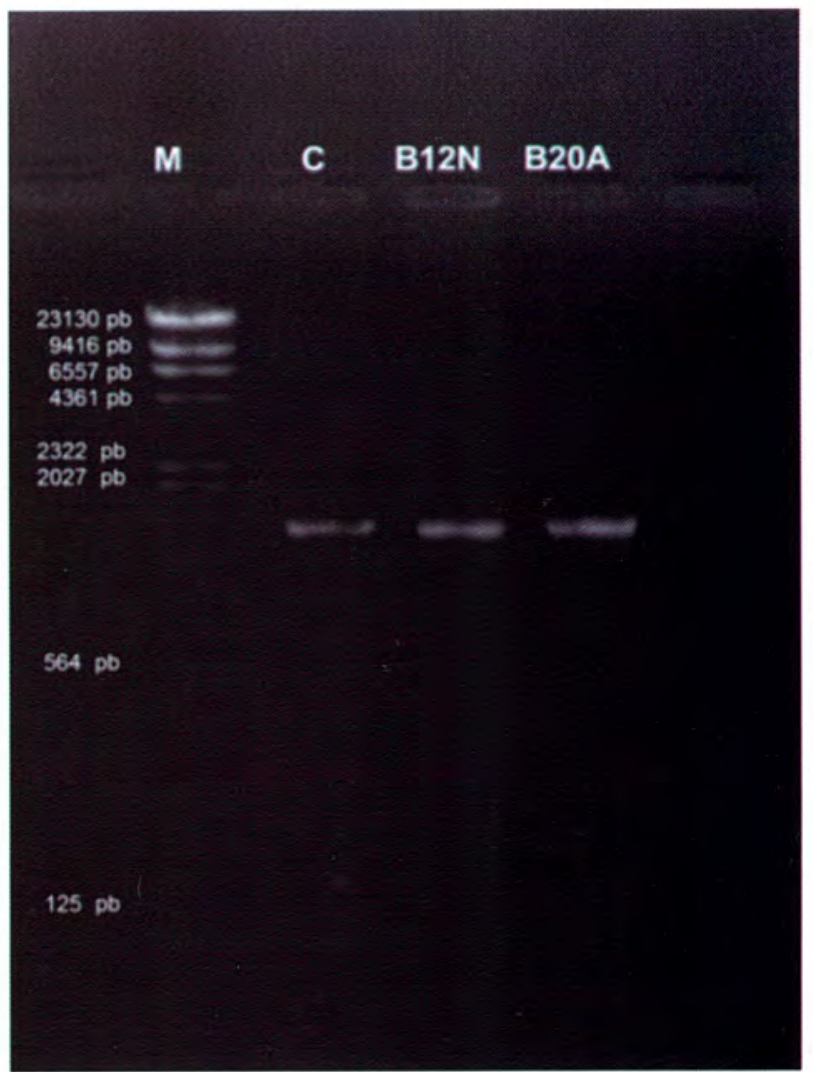

* M: marcador Hind III de 23130 pb, C: cepa control Escherichia colit.

Figura $\mathbf{N}^{\circ}$ 07. Electroforesis de PCR de las cepas B12N y B20A. 
Zapata, H. y Castellanos, R., Aislamiento e identificación de bacterias celulolíticas termófilos de géiseres naturales de Candarave - Tacna.

BLAST), que mayor similitud presenta con la bacteria problema, indicando el porcentaje de identidad y el porcentaje de la secuencia que ha sido comparada.

\section{DISCUSIÓN}

\section{Aislamiento}

La muestra extraida de la fuente termal $\mathrm{T}_{3}$ permitió el mayor número de UFC con $6,3 \times 10^{3} \mathrm{UFC} \mathrm{ml}^{-1}$ en el medio de aislamiento selectivo con CMC, posiblemente sus características fisicoquímicas son favorables para el desarrollo de microorganismos productores de celulasas, como la temperatura de $70^{\circ} \mathrm{C}$ y $\mathrm{pH}$ neutro, que facilitan que bacterias esporógenas y actinomicetos incrementen su actividad y por ende su población (Granados \& Valderrama, 2003). Además la naturaleza de la muestra tipo tapetes microbianos se caracteriza por presentar altas densidades de población de microorganismos y es utilizada con éxito para recuperar nuevos organismos. Los tapetes microbianos además de presentar en su mayoría comunidades fotoautótrofas, también poseen comunidades quimioorganotrofas característico de los microorganismos con celulasas (Nord \& Wald, 1995; De Beer \& Kühl, 2001).

De los 31 cultivos bacterianos aislados hay una predominancia de bacterias Gram positivas con $61,29 \%$, sin embargo Valdez (2011) reportó predominancia de bacterias Gram negativas en los géiseres evaluados de Calientes, esto debido a que según Debord (1925) las bacterias termófilas suelen presentar una coloración Gram variable, donde ciertos organismos termófilos que forman esporas son Gram negativos a las $24 \mathrm{~h}$ y Gram positivas a las $8 \mathrm{~h}$, debido a su metabolismo muy acelerado.

\section{Actividad cualitativa}

Se sabe que las celulasas bacterianas tienen actividades bastantes altas y más termoestables comparadas con las celulasas fúngicas (Swaroopa et al., 2004), teniendo en cuenta esta ventaja, se pre-seleccionaron 6 cultivos con actividad de celulasas, con halos de hidrólisis significativos, indicando su habilidad para producir celulasas, dado que el colorante Rojo Congo presenta fuertes interacciones con polisacáridos unidos por enlaces $\beta-1,4$ asi como significantes interacciones con $\beta-1,3-\mathrm{D}$ - glucanos, al producirse la hidrólisis de estos compuestos, las interacciones entre el colorante y los polisacáridos se pierden, notándose áreas desteñidas correspondientes al área en el que la bacteria secretó las celulasas.

\section{Actividad cuantitativa de endoglucanasas}

$\mathrm{Al}$ optimizar los factores de $\mathrm{pH}$ y temperatura, de los cuales, según Nataraja et al. (2010), depende la mayor actividad enzimática de endoglucanasas. Se obtuvo para la cepa B12N de una gradiente de temperaturas entre 60 y 80 ${ }^{\circ} \mathrm{C}$ con $\mathrm{pH}$ de entre 4,4 y 8,4 que el $\mathrm{pH}$ óptimo es 5,9 y la temperatura $67,5^{\circ} \mathrm{C}$, registrando una actividad máxima de $0,56 \mathrm{UI} \mathrm{ml}^{-1}$, valor mayor al registrado por Montoya (2012) quien reporta una actividad de $0,34 \mathrm{UI} \mathrm{ml}^{-1}$ a un valor óptimo a $65^{\circ} \mathrm{C}$ y un $\mathrm{pH}$ de 6 para una cepa de Bacillus sp. BH19.

Para la cepa B20A se observó de una gradiente entre 50 y $75^{\circ} \mathrm{C}$ con un $\mathrm{pH}$ entre 4,4 y 9,4 que el $\mathrm{pH}$ óptimo es 6,4 y la temperatura $59,5^{\circ} \mathrm{C}$, dando una actividad máxima

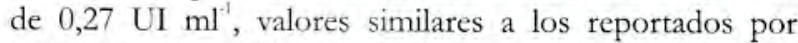
Montoya (2012) y Li et al. (2008), en la cepas de Bacillus sp. BH62 y Bacillus subtilis, sin embargo la cepa B20A presenta ventaja sobre las estudiadas por presentar una temperatura óptima superior en 14 y $10^{\circ} \mathrm{C}$ respectivamente.

Por lo tanto de acuerdo a la temperatura óptima para su actividad enzimática, se puede considerar a las enzimas termoestables, tal como Rastogi et al. (2010) consideró endoglucanasas termoestables a $70{ }^{\circ} \mathrm{C}$ y un $\mathrm{pH}$ óptimo de 5 en cepas de Geobacillus y Bacillus aisladas de muestra de compost; Bischoff et al. (2006) encontraron endoglucanasas termoestables a $65^{\circ} \mathrm{C}$ a un $\mathrm{pH} 6$ en Bacillu. licbeniformis. Dichas enzimas son de importancia en bioprocesamientos, por las posibilidades de almacenamiento prolongado (a temperatura ambiente), el aumento de la tolerancia a disolventes orgánicos, la reducción del riesgo de contaminación, así como las pérdidas de baja actividad durante el procesamiento, incluso a las temperaturas elevadas a menudo utilizadas en el pre-tratamiento de la materia prima (Kristjansson, 1989; Pernilla et al., 2007).

\section{Determinación de biomasa y cuantificación de proteinas solubles}

La actividad celulolítica no es parte del metabolismo primario de los microorganismos (etapa de crecimiento) sino que estaría asociada a la resistencia (Lynd et al., 2002), tal como se observó en los cultivos bacterianos seleccionados los cuales a pesar de presentar valores de biomasa similar tienen actividades enzimáticas distintas por lo tanto no hay una relación directa entre la biomasa producida y la actividad enzimática.

$\mathrm{Al}$ analizar las cepas en función de la producción de biomasa, la cepa B12N y B20A presentaron $0,05 \mathrm{mg} \mathrm{ml}^{-1} \mathrm{y}$ $0,06 \mathrm{mg} \mathrm{ml}^{-1}$ de medio de producción respectivamente, indicando bajos niveles de producción de masa celular por $\mathrm{ml}$ de medio, lo cual es ventajoso en procesos industriales en la separación de la biomasa de los metabolitos de interés.

Otro de los parámetros a tener en cuenta en la selección de microorganismos celulolíticos es la actividad enzimática en función a la biomasa (AEB), de donde se observó ventajas en las cepas termófilas seleccionadas, con un rendimiento bastante promisorio, ya que al generarse una baja biomasa se produce valores significativos de actividad enzimática obteniéndose valores de 11,2 UI $\mathrm{mg}^{-1}$ y $4,5 \mathrm{UI}$ $\mathrm{mg}^{-1}$ para las cepas $\mathrm{B} 12 \mathrm{~N}$ y $\mathrm{B} 20 \mathrm{~A}$ respectivamente, superando a lo reportado por Ramírez y Coha (2003) quienes obtuvieron 1,18 y $0,90 \mathrm{UI} \mathrm{mg}^{-1}$ de biomasa para Streptomycessp. 28CMC2 y Thermomonospora curvata 7CMC8.

La actividad específica de las endoglucanasas por proteínas (AEP), indica la pureza de la enzima, por tanto es de mucha importancia contar con cepas con elevadas actividades específicas, mostrando valores significativos la cepa B12N con 18,66 UI mg de proteína lo cual está acorde a lo reportado por Ramírez y Coha (2003), quienes obtuvieron 20,14 UI mg de proteína para Streptomyces sp. $7 \mathrm{CMC10}$; sin embargo la actividad se presenta a menor temperatura que la reportada en nuestro estudio. 


\section{Análisis del secuenciamiento del ARNr 16S}

Del alineamiento del secuenciamiento del gen ARNr $16 \mathrm{~S}$ con el Genbank ambas cepas se alinearon a los filotipos Firmicutes, lo cual coincide con Valdez (2011) en su análisis molecular del ARNr $16 \mathrm{~S}$ de los géiseres de Calientes.

La cepa B12N presenta un $99 \%$ de identidad con la cepa Geobacillus sp. JC106 aislada de aguas termales con azufre en Maharashtra (India) y la cepa B20A tiene un $97 \%$ de identidad con la cepa Bacillus licheniformis strain F3 aislada de salchichas secadas al aire en China, lo cual indica su naturaleza adaptativa a diferentes ambientes. Ambos valores hallados de identidad entre genes $\mathrm{ARNr} 16 \mathrm{~S}$ son mayores o iguales al $97 \%$, lo cual es aceptado para ejercer relación entre las cepas a nivel de especie (Stackebrandt \& Göbel, 1994).

\section{CONCLUSIONES}

Las fuentes termales de Calientes, Candarave Tacna, muestran un gran potencial ya que poseen bacterias con celulasas de interés industrial, donde el $77,42 \%$ de los 31 cultivos bacterianos aislados presentan zonas de hidrólisis en CMC.

Se logró determinar cuantitativamente y optimizar los factores (temperatura y $\mathrm{pH}$ ) de los que depende la actividad de endoglucanasas, obteniéndose $0,56 \mathrm{UI} \mathrm{ml}^{-1}$ a $67,5^{\circ} \mathrm{C}$ y un $\mathrm{pH} 6$ y $0,27 \mathrm{UI} \mathrm{ml}^{1}$ a $59,5^{\circ} \mathrm{C}$ y un $\mathrm{pH} 6,4$; para las cepas $\mathrm{B} 12 \mathrm{~N}$ y $\mathrm{B} 20 \mathrm{~A}$ respectivamente.

La temperatura óptima para la mayor actividad enzimática registrada fue superior a la temperatura de crecimiento, por lo tanto las enzimas aisladas son consideradas termoestables.

La producción de biomasa de las cepas seleccionadas no fue en su totalidad directamente proporcional al nivel de producción de endoglucanasas, indicando su independencia con el crecimiento bacteriano, por lo tanto podrían ser enzimas adaptativas.

Se logró la identificación molecular de las cepas seleccionadas B12N y B20 con una similitud del $99 \%$ con Geobacillus sp. y $97 \%$ con Bacillus licheniformis respectivamente.

\section{AGRADECIMIENTO}

Al Laboratorio de Micología y Biotecnología (LMB) de la Universidad Nacional Agraria La Molina.

\section{REFERENCIAS BIBLIOGRÁFICAS}

Bhalla, A., Bansal, N., Kumar, S., Bischoff, K. \& Sani, R. (2013). Improved lignocellulose conversion to biofuels with thermophilic bacteria and thermostable enzymes. Bioresource Technology, 128 pp. 751-759.

Bischoff, K., Rooney, A., Li, X., Liu, S. \& Hughes, S., (2006). Purification and characterization of a family 5 endoglucanase from a moderately thermophilic strain of Bacillus licheniformis. Journal of Biotecbnology Lett, 28(21) pp. 1761-5.

Cruz, V., Frich, V. \& Matsuda, K. (2010). Geochemical characterization of thermal waters in the Calientes geothermal field, Tacna, South of Peru. Proceedings world geothermal congress 2010, Indonesia. p.1.

De Beer, D. \& Kühl, M. (2001). Interfacial microbial mats and biofilms. In: Boudreau, B. Jorgensen, B. (Eds.), The Benthic Boundary Layer, Oxford University Press, New York, pp. 374-394.

Debord, G. (1925). Reaction to Gram's stain by certain spore-forming bacteria. Proceedings of the Society for Experimental Biology and Medicine, 22 pp. 397-398.

Ghose, T. (1987). Measurement of cellulase activities. Pure and Applied Chemistry, 59 (2) pp. 257-268.

Granados, L. \& Valderrama, J. (2003). Evaluación de la actividad proteolitica y amilolitica de actinomycetes termofilicos aislados a partir de pilas de compost. Tesis de pregrado en Microbiología Industrial. Pontificia Universidad Javeriana. Bogotá.

Hernández A., García E. \& Romero H. (1999). Celulosomas: sistemas multienzimáticos. Revista SociedadQuímica de México 43 (3-4) pp. 137-142.

Hongpattarakere T. (2002). Hyperthermostable cellulolytic and hemicellulolytic enzymes and their biotechnological applications. Songklanakarin Journal Science \& Technology. 24(3) pp. 481-491.

Kristjansson, JK. (1989). Thermophilic organisms as sources of thermostable enzymes. Trends in Biotechnology, 7 pp. 349-353.

Kublanov, I., Perevalova, A., Slobodkina, G., Lebedinsky, A., Bidzhieva, S., Kolganova, T., Kaliberda, E., Rumsh, L., Haertle, T. \& Bonch - Osmolovskaya, E. (2009) Biodiversity of thermopbilic prokaryotes with bydrolytic activities in bot springs of Uzon Caldera, Kamchatka (Russia). Applied and Environmental Microbiology, 75(1) pp. 286-291.

Li, W., Zhang, W., Yang, M., \& Chen, Y., (2008). Cloning of the thermostable cellulase gene from newly isolated Bacillus subtilis and its expression in Escherichia coli. Journal of Molecular Biotechnology, 40 (2) pp. 195 201.

Lowry, O., Rosenbrough, N., Farr, A. \& Randall R. (1951). Protein measurement with the Folin phenol reagent. Journal of Biological Chemistry, 193 pp. 265-275.

Lymar, E., Li, B. \& Renganathan, V. (1995). Purification and Characterization of a cellulose-binding $\beta$-glucosidase from cellulose degrading cultures of Phanaerochaete chrysosporium. Applied Environmental Microbiology, 8 pp. 2976 2980.

Lynd, L., Weimer, P., Zyl, W. \& Pretorius, I. (2002). Microbial cellulose utilization: Fundamentals and Biotechnology. USA. Microbiology and Molecular Biology Reviews, 66(3) pp. 506- 577.

Mandels, M. \& Reese, E. (1957). Induction of cellulase in Trichoderma viride as influenced by carbon sources and metals. Journal of Bacteriology, 73(2) pp. 269-278.

Martínez, A., Speranza, M., Ruiz Dueñas, F., Ferreira, P., Camarero, S., Guillen, F., Martínez, M., Gutiérrez, A. \& Del Río, J. (2005). Biodegradation of lignocellulosics: microbial, chemical and enzymatic aspects of fungal attack of lignin. International Microbiology: the official journal of the Spanish Society for Microbiology 8(3) pp. 195-204. 
Zapata, H. y Castellanos, R., Aislamiento e identificación de bacterias celulolíticas termófilos de géiseres naturales de Candarave - Tacna.

Meza, V., Moreno, P., Tengerdy, R. \& Gutiérrez, M. (1995). Transfer of a benomyl resistance marker by heatinactivated Trichoderma reesei protoplasts. Biotechnology Letters, $17(8)$ pp. 827-832.

Miller, L. (1959). Use of dinitrosalicylic acid reagent for determination of reducing sugar. Analytical Chemistry, 31 pp. 426-428.

Montoya, R. (2012). Selección de cepas de Bacillus sp. potenciales para la producción de bidrolasas. Centro Nacional de Pesquia en Energia e Materiais. Universidad Autónoma de Aguascalientes, México.

Nataraja, S., Chetan, D. \& Krishnappa, M. (2010), Effect of temperature on cellulose enzyme activity in crude extracts isolated from solid wastes microbes. International Journal of Microbiology Research, 2 (2) pp. 44-47.

Nord, S. \& DM, Ward. (1995). Diverse Thermus species inbabit a single bot spring microbial mat. Systematic and Applied Microbiology, 18 pp. 274-278.

Pérez, J., Muñoz, J., De la Rubia, T. \& Martínez, J. (2002). Biodegradation and biological treatments of cellulose, bemicellulose and lignin: an overview. International Microbiology 5(2) pp. 53-63.

Pernilla, T., Gashaw, M. \& Nordberg, E. (2007). Potential and utilization of thermophiles and thermostable enzymes in biorefining. Journal of Microbial Cell Factories, pp. 6-9.

Ramírez, P. \& Coha, J. (2003). Degradación enzimática de celulosa por actinomicetos termófilos: Aislamiento, caracterización y determinación de la actividad celulolítica. Revista Peruana de Biologia, 10(1) pp. 67-77.

Rastogi, G., Bhalla, A., Adhikar, A., Bischoff, K., Hughes, S.,
Christopher, L. \& Sani, R. (2010). Characterization of thermostable cellulases produced by Bacillus and Geobacillus strains. Journal of Bioresource Technology, 101(22), pp. 8798-8806.

Sambrook, J. \& Russell, D. (1989). Molecular cloning: a laboratory manual. Cold Spring Harbor Press, New York.

Stackebrandt, E. \& Goebel, B. (1994). Taxonomic Note: A Place for DNA-DNA reassociation and $165, r R N A$ sequence analysis in the present species definition in bacteriology. International Journal of Systematic Bacteriology, 44 pp. 846-849.

Swaroopa, D. Thirumale, S. \& Nand, K. (2004). Production of cellulose by Clostridium papyrosolvens CFR703. Journal of Microbiology and Biotechnology, $20 \mathrm{pp}$. 629-632.

Teather, R. \& Wood, P. (1982). Use of Congo red-polysaccharide interactions in enumeration and characterization of cellulolytic bacteria from the bovine rumen. Applied and Environmental Microbiology, 43 (4) pp.777-780.

Valdez, Y. (2011). Caracterización molecular y determinación de la diversidad microbiana para bacterias y arqueas bipertermófilas de los géiseres de Calientes, Candarave, Tacna- Perú. Tesis de pregrado en Biología. Universidad Nacional Jorge Basadre Grohmann, Tacna.

Wessel, D. \& Fluegge, U. (1984). Analytical Biochemistry, 138 pp. 141-143.

Zhang, Y., Himmel, M. \& Mielenz, J. (2006). Outlook, for cellulase improvement: Screening and selection strategies. Biotechnology Advances, 24 pp. 452- 481.

\section{Correspondencia:}

Helena Beatriz Zapata Málaga: hbzapata@gmailcom

Roberto Castellanos C.: robertocastellanoscabrera@yahoo.es
Fecha de Recepción: 17/10/2014

Fecha de Aceptación: 03/12/2014 